\title{
Path and Mechanism of Blockchain Embedded in Innovation Management of Cultural and Creative Industrial Park
}

\author{
Huilan Wei ${ }^{1}$ and Shunfeng Guan $\mathbb{D}^{2}$ \\ ${ }^{1}$ School of Industrial Design, Hubei University of Technology, Wuhan 430070, China \\ ${ }^{2}$ School of Art and Design, Wuhan University of Technology, Wuhan 430070, China \\ Correspondence should be addressed to Shunfeng Guan; 9863@whut.edu.cn
}

Received 1 June 2021; Revised 22 June 2021; Accepted 5 July 2021; Published 13 July 2021

Academic Editor: Guangdong Wu

Copyright (C) 2021 Huilan Wei and Shunfeng Guan. This is an open access article distributed under the Creative Commons Attribution License, which permits unrestricted use, distribution, and reproduction in any medium, provided the original work is properly cited.

\begin{abstract}
As a new business form of Cultural and Creative Industrial Cluster, the management of Cultural and Creative Industrial Park is faced with many difficulties, such as imperfect credit mechanism, lagging efficiency of intellectual property management, difficulties in industrial chain integration and upgrading, and imperfect development evaluation system. The "decentralization" concept of blockchain 3.0 technology can provide guidance value for the management concept innovation of Cultural and Creative Industry Park, and the embedding of technologies such as "smart contract", "distributed ledger", and "digital currency" can promote the construction of "programmable management system of Cultural and Creative Industry Park". According to the analysis path of architecture, function system, and application scenario of park management, this paper constructs the architecture from consensus layer, network layer, and data layer, constructs the function system from the public chain, alliance chain, and private chain, and locates the application scenario from the dimensions such as industrial chain management and government supervision and management; thus, the direction and focus of management innovation of blockchain 3.0 technology embedded in Cultural and Creative Industry Park are clarified. The research results of this paper have good theoretical guidance for the management subjects of Cultural and Creative Industry Park (local government, park management committee, industry organizations, etc.) to determine the path of implementing management innovation by using blockchain 3.0 and to build a scientific park management mechanism.
\end{abstract}

\section{Introduction}

In 2020, blockchain has been included in the outline of the 14th five-year plan for China's national economic and social development, listed as an important part of the digital economy industry, and a new engine to promote the deep integration of digital technology and the real economy. As a new technological innovation, the main value of blockchain is to provide data management technology, credit mechanism solutions, and a "decentralized" management philosophy. On the one hand, blockchain can provide underlying technical support for emerging technologies such as AI, Big Data, and IOT and promote their collaborative innovation and application. On the other hand, with the advent of the era of Blockchain 3.0 "programmable society", the application of blockchain in the financial industry, copyright industry, energy industry, education industry, social welfare, and other fields is deepening, and its wide application has strategic guiding significance.

Cultural and Creative Industrial Park is the gathering of culture, innovation, art, design, and other industries in a specific area of the city, which is composed of various enterprises such as creativity, manufacturing, communication, and consumption. It is also an important symbol of the city's cultural image which is characterized by spatial agglomeration, functional diversification, and a low-carbon economic model. The planning and construction of the Cultural and Creative Industrial Park is an important link and key task to boost the cultural industry to become a pillar of the national economy. The "fourteenth five-year development plan of the 
national economy" proposes implementing the digital strategy of cultural industry, which points out a new direction for the management innovation of Cultural and Creative Industry. Cultural and Creative Industry Park is a complex self-organization system, its management is a complex system engineering, and the management object includes the park strategy, resources, marketing, and operation. Blockchain 3.0 provides ideological guidance and technical support for the construction of the digital management platform of Cultural and Creative Industry Park. It can not only provide ideas and paths for the management innovation of Cultural and Creative Industry Park on the technical level but also promote the coupling effect and innovate the management mechanism of Cultural and Creative Industry Park.

Exploring the path and mechanism of blockchain 3.0 embedded in the management innovation of Cultural and Creative Industry Park will not only help to find a new way to solve the dilemma of traditional park management through expanding the application value of blockchain technology in the field of real economy but also help to achieve the strategic goal of cultural industry digitization through innovating the management mode of Cultural and Creative Industry Park.

\section{Literature Review}

2.1. Management System and Technical Innovation of Blockchain 3.0. Blockchain 3.0 has two meanings: one is the progress and breakthrough from "decentralization" to "smart contract" and then to "intelligent IOT" on the technical level; the other is the breakthrough extension from "programmable currency" represented by Bitcoin to "programmable finance" represented by Ethereum and then to "programmable society" [1]. The management system and technological innovation of blockchain 3.0 can be understood from three levels: "decentralization", "smart contract", and "distributed data". The relationship between them is shown in Figure 1.

2.1.1. Decentralized Management System. At the beginning of the birth of blockchain, "decentralization" has become its core, which realizes the weakening of the center and the construction of the programming self-organization operation system on the technical level. According to the design of Satoshi Nakamoto, the core economic operation system of the blockchain is "competition-bookkeeping-reward" [2], and they are interrelated based on data technology to form a self-organization management system containing each other. Compared with the traditional human-centered management system, this system has two major advantages: first, "decentralization" can weaken the subjective, bias, and deviation errors in management and avoid the risks and losses; the second is to give full play to the advantages of technical rationality and carry out system operation management based on network programming technology.

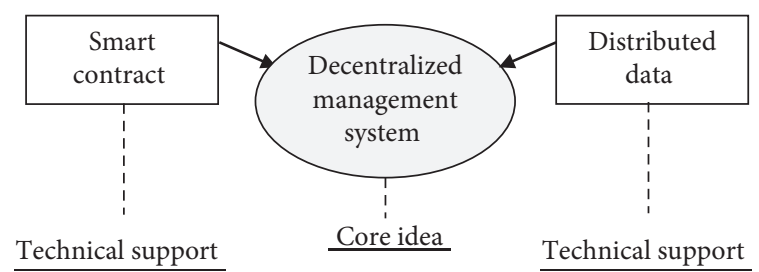

FIGURE 1: Management system and technical support of Blockchain 3.0.

The management system of "decentralization" of blockchain depends on the technical support of "functional contract" and "distributed data".

2.1.2. Smart Contract Technology Innovation. The smart contract is a concept put forward by Nick Szabo in the 1990s, which was born at the same time as the Internet [3]. The characteristic of the smart contract is that once it is set up, it can be executed automatically without the participation of an intermediary, and no one can stop it from running. Taking Ethereum's smart contract as an example, it is the code on the blockchain composed of a series of programming languages, such as Solidity, Serpent, Lisp-Like Language, and Mutan. The user writes the designed business logic into a smart contract and deploys it in Ethereum, which is automatically executed by Ethereum Virtual Machine (EVM) [4].

The functional contract management system is a collection of a series of underlying technologies, which together support the formation of smart contracts and solve the credit mechanism problem in the blockchain. Specifically, technologies to solve consensus and credit problems based on pluggable consensus templates mainly include PoW, PoS, DpoS, Pbft, Raft, Casper, and PoET. The intelligent IOT is the evolution of intelligent contract technology. Combined with the IOT, it can broaden the application of blockchain in the field of the real economy and promote the continuous development of blockchain technology.

\subsubsection{Data Management Technology Innovation. Data} management technology of blockchain originated from "encrypted distributed ledger", whose breakthrough innovation is to break the trust problem and information storage security problem of traditional central bookkeeping. The data management of blockchain solves the problem of information security through the mechanism of cryptography and the use of data programming means, distributed to each node to record data, in order to ensure that data records are not tampered with.

The technical elements of distributed data management include block data, digital signature, chain structure, hash algorithm, Merkle tree, and asymmetric encryption. Digital currency is a unique distributed database. Its purpose is to realize the point-to-point payment of virtual currency and avoid the problem of double spending in finance. 
2.2. Feasibility Analysis of Blockchain 3.0 Embedded in Cultural and Creative Industrial Park Management Innovation. The extensive exploration of blockchain in the management and operation of other industries provides a reference for its practical application in the management of Cultural and Creative Industry Park. At present, there are some urgent difficulties in the management of Cultural and Creative Industry Park, such as financing difficulties, high cost of industrial value chain operation and data management, credit mechanism among member enterprises, technical support weakness, and intellectual property protection and development. These dilemmas lead to the low efficiency of the management of Cultural and Creative Industry Park and the difficult evaluation of the park.

There are few researches and explorations on the application of blockchain technology in the management of cultural and creative industries. At present, it only involves copyright confirmation and transaction, product traceability and authentication, trust fund, and digital finance. Zhang and Luo [5] discussed the possibility of blockchain application in the art trust fund and digital finance; Yu et al. [6], based on the blockchain technology, designed the function modules of copyright registration, online preview, copyright trading, user rights protection, etc., and reconstructed the ceramic art design copyright trading platform; Wang [7] explored the application of blockchain technology in art identification; Ding discussed the application mode of "blockchain + art education".

In the meantime, blockchain technology has attracted extensive attention in theoretical and related industrial fields; it has been widely used in financial services, supply chain management, copyright management, intelligent manufacturing, social welfare, education, energy industry, file management, performance appraisal, sharing economy, etc. The exploration of blockchain in the field of the real economy has achieved certain progress, which has been tested by practice. The typical representative of its application in the field of commodity traceability is the "Jingdong blockchain anti-counterfeiting traceability platform", which realizes the traceability and anti-counterfeiting of online and offline retail commodities in the form of alliance chain. In the field of copyright protection and trading, Xiamen Annie Co. Ltd. is connected with the official copyright institutions through an alliance chain, which improves the efficiency of confirmation and trading of copyright digital. In the field of precision marketing, the "marketing data link" platform jointly built by LEO Digital Network and MI has distributed records of Internet advertising monitoring, bidding, exposure, click, and follow-up behavior logs. Through marketing data cooperation, the data efficiency and value are maximized. In addition, the application of blockchain in the field of IOT, digital identity, and E-government has also made some achievements [8].

To sum up, blockchain technology has made some achievements in the application of the real economy. Although these application modes and paths cannot be directly applied to the management innovation of Cultural and Creative Industrial Park, they provide a certain reference value for blockchain to boost the programmable management of Cultural and Creative Industrial Park. The management system of blockchain is coupled with the management system of Cultural and Creative Industry Park. Blockchain can provide technical support for management innovation of Cultural and Creative Industry Park. It has a solid theoretical and practical foundation to explore the path and mechanism of blockchain promoting the management innovation of Cultural and Creative Industry Park.

\section{Methodology}

3.1. Method Explanation. In order to express the relationship of factor sets more directly, this study sets the elements of Blockchain 3.0 as $X$, the management function of Cultural and Creative Industry Park as $Y$, and the functional elements of the park as $A$. Next, this study uses the Likert scale to score the correlation between $X$ and $Y, Y$, and $A$, respectively, through expert interviews.

$$
\begin{aligned}
& X=\left\{X_{1}, X_{2}, X_{3}\right\}, \\
& Y=\left\{Y_{1}, Y_{2}, Y_{3}, Y_{4}\right\}, \\
& A=\left\{A_{1}, A_{2}, A_{n}, \ldots, A_{11}\right\} .
\end{aligned}
$$

Among them, $X_{1}, X_{2}$, and $X_{3}$ represent distributed data, smart contract, and digital currency of Blockchain 3.0, respectively; $Y_{1}, Y_{2}, Y_{3}$, and $Y_{4}$ represent planning, organization, leadership, and control of management means of Cultural and Creative Industry Park, respectively; $A_{1}, A_{2}, A_{\mathrm{n}}$ ... and $A_{11}$ represent public relations management, intermediary service, IP copyright management, personnel management, enterprise/institution management, financial management, industrial chain management, IOT management, equipment and technology management, government supervision, customer management, public relations management, and intermediary service management, respectively. Two groups of factors that need to be scored are " $X-Y$ " and " $Y-A$ "; they express "the relevance between Blockchain 3.0 and the management functions of Cultural and Creative Industry Park" and "the relevance between Blockchain 3.0 and the management functions and elements of Cultural and Creative Industry Park", respectively. The score of $\{5,4,3,2,1\}$ in Likert's scales represents the degree of correlation. Two survey scales are shown in Tables 1 and 2.

The correlation degree is $R$ and the expert score is $C$. The function expression of the two factors is as follows:

$$
\begin{aligned}
& R_{n}=\left\{R_{1}, R_{2}, \ldots, R_{n}, \ldots R_{12}\right\}, \\
& C_{n}=\left\{C n_{1}, C n_{2}, C n_{3}, C n_{4}, C n_{5}\right\}, \\
& R n=\frac{C n_{1}+C n_{2}+\ldots+C n_{5}}{5}=\frac{\sum_{i=1}^{5} C n_{i}}{5} .
\end{aligned}
$$

3.2. Data Sources. In this study, five experts were invited to participate in the study to determine the relevance between Blockchain 3.0 and the management means and 
TABLE 1: Research on the correlation between Blockchain 3.0 and the management means of Cultural and Creative Industry Park.

\begin{tabular}{cccc}
\hline & $X_{1}$ & $X_{2}$ & $X_{3}$ \\
\hline$Y_{1}$ & $(5,4,3,2,1)$ & $(5,4,3,2,1)$ & $(5,4,3,2,1)$ \\
$Y_{2}$ & $(5,4,3,2,1)$ & $(5,4,3,2,1)$ & $(5,4,3,2,1)$ \\
$Y_{3}$ & $(5,4,3,2,1)$ & $(5,4,3,2,1)$ & $(5,4,3,2,1)$ \\
$Y_{4}$ & $(5,4,3,2,1)$ & $(5,4,3,2,1)$ & $(5,4,3,2,1)$ \\
\hline
\end{tabular}

TABLE 2: Research on the correlation between management functions and elements of Blockchain 3.0 embedded in Cultural and Creative Industry Park.

\begin{tabular}{ccccc}
\hline & $A_{1}$ & $A_{2}$ & $\ldots$ & $A_{11}$ \\
\hline$Y_{1}$ & $(5,4,3,2,1)$ & $(5,4,3,2,1)$ & $\ldots$ & $(5,4,3,2,1)$ \\
$Y_{2}$ & $(5,4,3,2,1)$ & $(5,4,3,2,1)$ & $\ldots$ & $(5,4,3,2,1)$ \\
$Y_{3}$ & $(5,4,3,2,1)$ & $(5,4,3,2,1)$ & $\ldots$ & $(5,4,3,2,1)$ \\
$Y_{4}$ & $(5,4,3,2,1)$ & $(5,4,3,2,1)$ & $\ldots$ & $(5,4,3,2,1)$ \\
\hline
\end{tabular}

management elements of Cultural and Creative Industry Park, respectively. They completed all the Likert scales in Tables 1 and 2 .

3.3. Data Validation. Kurtosis and skewness were used to test the data.

The calculation formula of kurtosis is as follows:

$$
K=\frac{(1 / n-1) \sum_{i=1}^{n}\left(x_{i}-\bar{x}\right)^{4}}{\operatorname{SD}^{4}}-3 .
$$

In the formula, $K$ is kurtosis; $i$ is serial number; $\overline{\mathrm{x}}$ represents the average value; $n$ is the number of samples; SD represents standard deviation.

The calculation formula of skewness is as follows:

$$
S=\frac{(1 / n-1) \sum_{i=1}^{n}\left(x_{i}-\bar{x}\right)^{3}}{\operatorname{SD}^{3}} .
$$

In the formula, $S$ is skewness, $i$ is serial number, $\bar{x}$ represents the average value, $n$ is the number of samples, and $\mathrm{SD}$ represents standard deviation.

\section{Results and Findings}

4.1. Association Mapping Model of Blockchain 3.0 and Cultural and Creative Industry Park Management. From the perspective of the management system, Blockchain 3.0 and Cultural and Creative Industrial Park are both complex operation systems, showing complex scientific management philosophy, creative management philosophy, and game theory management philosophy.

4.1.1. Complex Scientific Management Thinking Mode. It is a new management thinking mode formed and developed in the 21 st century. Its core is system thinking mode, and the management object is a complex system with self-organization, self-adaptability, and dynamic. The "decentralized" management system of Blockchain 3.0 realized by software programming technology is essentially a self-organizing and adaptive dynamic operation process realized by script programming and hardware facilities. Although there are three types of management modes of Cultural and Creative Industry Park: government-led, market-led, and mixed-led [9], the operation is also a complex adaptive system, which has the characteristics of self-organization, self-adaptation, and dynamic. The main performance is that the constituent elements of Cultural and Creative Industry Park are complex and diverse, they constitute a complex system, and their evolution process shows the self-organization characteristics of industrial organization evolution.

4.1.2. Creative Management Thinking Mode. It is also the common management thinking mode in the management of Blockchain 3.0 and Cultural and Creative Industrial Park which runs through the whole management process. The management activities of both are essentially continuous creation and innovation. The creativity of Blockchain 3.0 is mainly reflected in the development and innovation of new technologies such as consensus mechanism, encryption algorithm, data storage mode, data dissemination mechanism, and data verification mechanism. The creativity in the management of Cultural and Creative Industrial Park is mainly reflected in the innovation of the subject's management thinking model and management technology.

4.1.3. The Game Theory Management Mode. It is also a common feature in the management of blockchain and Cultural and Creative Industrial Park. The consensus mechanism and equal trading rights in the blockchain are all based on the core of game theory; The competition relations among enterprises in the Cultural and Creative Industrial Park, such as "zero-sum game", "positive-sum game”, and "negative-sum game", also reflect the idea of game theory.

In summary, the technical development and maturity of Blockchain 3.0 can provide technical support for the renewal of management means of Cultural and Creative Industrial Park. According to the research methods in 3.1, this paper collates the data of the management relevance between Blockchain 3.0 and Cultural and Creative Industrial Park Management; the results are shown in Table 3.

At the same time, the formulas (7) and (8) calculate the kurtosis $K=-1.16$ and skewness $S=-0.39$. The schematic diagram is as shown in Figure 2, and the data as a whole presents a flat right-skewed distribution.

In order to better describe the significance and value of Blockchain 3.0 for the management of Cultural and Creative Industrial Park, this paper calculated the correlation degree of the above 12 groups of factors according to formula (5), and the association mapping analysis model is made from the two levels of the management system and technical means, as shown in Figure 3.

4.1.4. Technical Support Association Mapping. The correlation degree of "distributed data" $\left(X_{1}\right)$ and $Y$ is 4.8, 4.8, 3.2, and 4.6, respectively, which can provide technical support for the data storage of enterprise/institution management, 
TABLE 3: Research data on the correlation between Blockchain 3.0 and the management means of Cultural and Creative Industry Park.

\begin{tabular}{llcccccccccccc}
\hline \multicolumn{1}{c}{$X_{1} Y_{1}$} & $X_{1} Y_{2}$ & $X_{1} Y_{3}$ & $X_{1} Y_{4}$ & $X_{2} Y_{1}$ & $X_{2} Y_{2}$ & $X_{2} Y_{3}$ & $X_{2} Y_{4}$ & $X_{3} Y_{1}$ & $X_{3} Y_{2}$ & $X_{3} Y_{3}$ & $X_{3} Y_{4}$ \\
\hline $\mathrm{C}_{1}$ & 5 & 5 & 3 & 5 & 5 & 5 & 4 & 5 & 4 & 4 & 4 \\
$\mathrm{C}_{2}$ & 5 & 4 & 3 & 4 & 5 & 5 & 4 & 5 & 3 & 4 & 3 \\
$\mathrm{C}_{3}$ & 4 & 5 & 4 & 5 & 4 & 5 & 3 & 4 & 4 & 4 & 3 \\
$\mathrm{C}_{4}$ & 5 & 5 & 3 & 5 & 5 & 5 & 4 & 5 & 4 & 3 & 4 \\
$\mathrm{C}_{5}$ & 5 & 5 & 3 & 4 & 5 & 5 & 4 & 5 & 5 & 4 & 3 \\
\hline
\end{tabular}

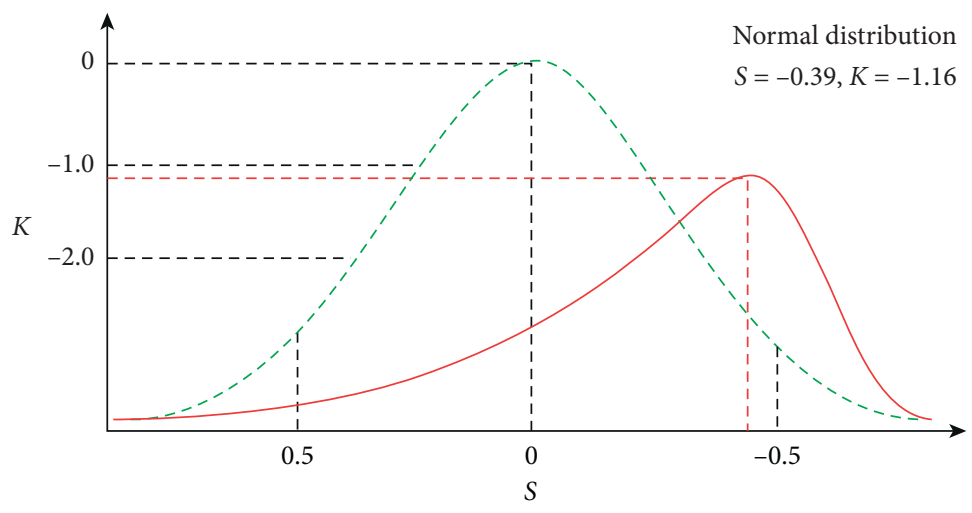

FIgURE 2: Kurtosis and skewness of data.

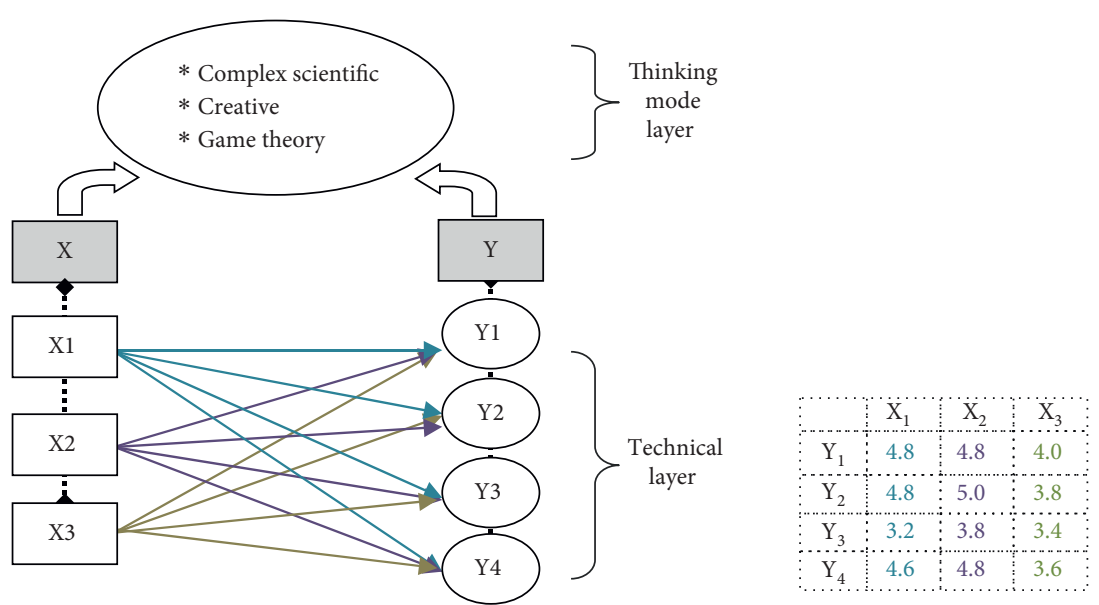

Figure 3: Association mapping model between Blockchain 3.0 and the management system of Cultural and Creative Industry Park.

policy management, resource management, and infrastructure management in the planning, organization, leadership, and control of Cultural and Creative Industrial Park Management and constantly update the data to form a block data chain to provide traceability and unchangeable data. The correlation degree of "smart contract" $\left(X_{2}\right)$ and $Y$ is 4.8 , $5.0,3.8$, and 4.8 , respectively, which can solve the consensus and rule problems in management activities. The electronic contract automatic execution program is compiled in the form of a smart contract, which can alleviate the cumbersome problems in traditional management. The correlation degree between "digital currency" $\left(X_{3}\right)$ and $Y$ is $4.0,3.8,3.4$, and 3.6, respectively. It can reduce the intermediate cost of legal currency circulation in value transmission activities, improve management efficiency and save management expenses, and avoid double spending.
4.2. Path of Blockchain 3.0 Technology Embedded in the Management Innovation of Cultural and Creative Industrial Park. By analyzing and processing the expert survey data of the relationship between programmable management objectives and framework elements of the Cultural and Creative Industry Park, this paper get the correlation degree data of the management functions and elements of the Cultural and Creative Industry Park embedded in Blockchain 3.0, as shown in Table 4.

At the same time, formulas (7) and (8) calculate the kurtosis $K=-1.22$ and skewness $S=0.66$. The schematic diagram is as shown in Figure 4, and the data as a whole presents a flat left-skewed distribution.

The results show that the average correlation degree of $A_{1}, A_{2}, A_{3}, A_{4}, A_{5}, A_{6}, A_{7}, A_{8}$, and $A_{9}$ is higher than 4.0 , while the average correlation degree of $A_{10}$ and $A_{11}$ is lower than 
TABLE 4: Correlation degree of management functions and elements of Blockchain 3.0 embedded in Cultural and Creative Industry Park.

\begin{tabular}{cccccccccccc}
\hline & $A_{1}$ & $A_{2}$ & $A_{3}$ & $A_{4}$ & $A_{5}$ & $A_{6}$ & $A_{7}$ & $A_{8}$ & $A_{9}$ & $A_{10}$ & $A_{11}$ \\
\hline$Y_{1}$ & 4.60 & 4.40 & 4.60 & 4.60 & 4.60 & 4.20 & 4.20 & 4.40 & 4.20 & 2.40 & 2.20 \\
$Y_{2}$ & 4.40 & 4.80 & 4.40 & 5.00 & 4.80 & 4.60 & 4.20 & 4.20 & 4.40 & 3.00 & 2.40 \\
$Y_{3}$ & 4.60 & 4.60 & 4.80 & 4.80 & 5.00 & 4.20 & 4.20 & 5.00 & 4.20 & 2.00 & 2.20 \\
$Y_{4}$ & 4.80 & 4.60 & 4.60 & 4.60 & 4.80 & 4.40 & 4.80 & 4.40 & 4.80 & 2.40 & 2.20 \\
$\bar{X}$ & 4.60 & 4.60 & 4.60 & 4.75 & 4.80 & 4.35 & 4.35 & 4.50 & 4.40 & 2.45 & 2.25 \\
\hline
\end{tabular}

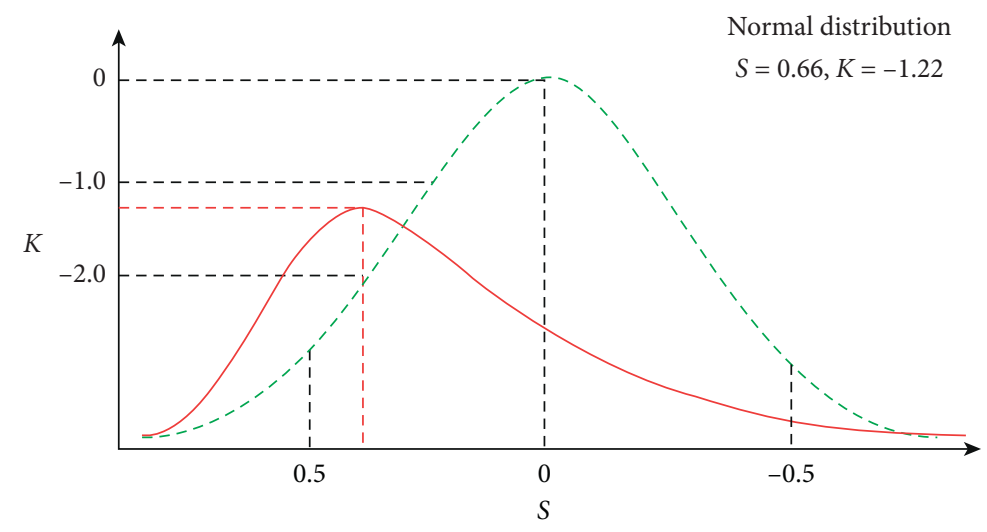

Figure 4: Kurtosis and skewness of data.

3.0. Therefore, this paper omits the two modules of public relations management module and intermediary service management module of Cultural and Creative Industry Park and constructs a "DAPP, Decentralized Application" composed of the data layer, technology layer, and application layer, as shown in Figure 5.

The data layer is located in the core position, which is composed of $\{1,2, \ldots, n\}$ blocks, building a decentralized cloud storage system. The technology layer is located in the middle, which is composed of link mechanism, propagation mechanism, verification mechanism, consensus mechanism, intelligent contract, asymmetric encryption, and other technologies. The application layer is located in the periphery and consists of nine application modules, which are IP copyright management module, government department supervision module, equipment and technology management module, customer management module, Internet of things management module, industrial chain management module, financial management module, enterprise/institution management module, and personnel management module.

In addition, according to the mode of participation, blockchain can be divided into a public chain, alliance chain, and private chain. Their characteristics and applicable scenarios are different. According to the principle of "Mundellian Trilemma" in economics, blockchain can only meet two goals at most among "decentralization", "security" and "efficiency". Public chain mainly realizes "decentralization" and "security", while alliance chain and private chain focus more on "efficiency" and "security". The architecture, categories, and application scenarios of Blockchain 3.0 in the programmable management system of Cultural and Creative Industry Park are shown in Figure 6.
The characteristic of the Permissionless/public chain is that there is no official organization and management organization; participating nodes have free access to the network and work based on consensus. Bitcoin and Ethereum are the most representative public chain applications. The main function of the public chain construction of Cultural and Creative Industry Park is to boost the construction of Digital Sharing Economy and Smart Park, realize the programmable management system construction of the park, and complete the strategic management innovation of the park.

The consortium blockchain is a limited blockchain and is only limited to the participation of alliance members. Alliance chain plays an important role in the operation and management innovation of Cultural and Creative Industry Park, which can promote the realization of "enterprise cooperation informatization" among alliance enterprises in the park, reach consensus through the mutual trust of multicenters, and realize the informatization business model of multiparty and peer-to-peer cooperation.

Private blockchain has a smaller scope of participation and generally exists in enterprises or project groups. Its main function is to provide a secure, traceable, and automatic computing platform for teamwork.

4.2.1. IP Rights Management Module. In terms of IP copyright management activities, technologies such as timestamp, encryption algorithm, and smart contract of Blockchain 3.0 provide technical support for efficient right confirmation, rights protection, and copyright transaction and solve problems such as right confirmation, use, transaction, license, and transfer of intellectual property, as 


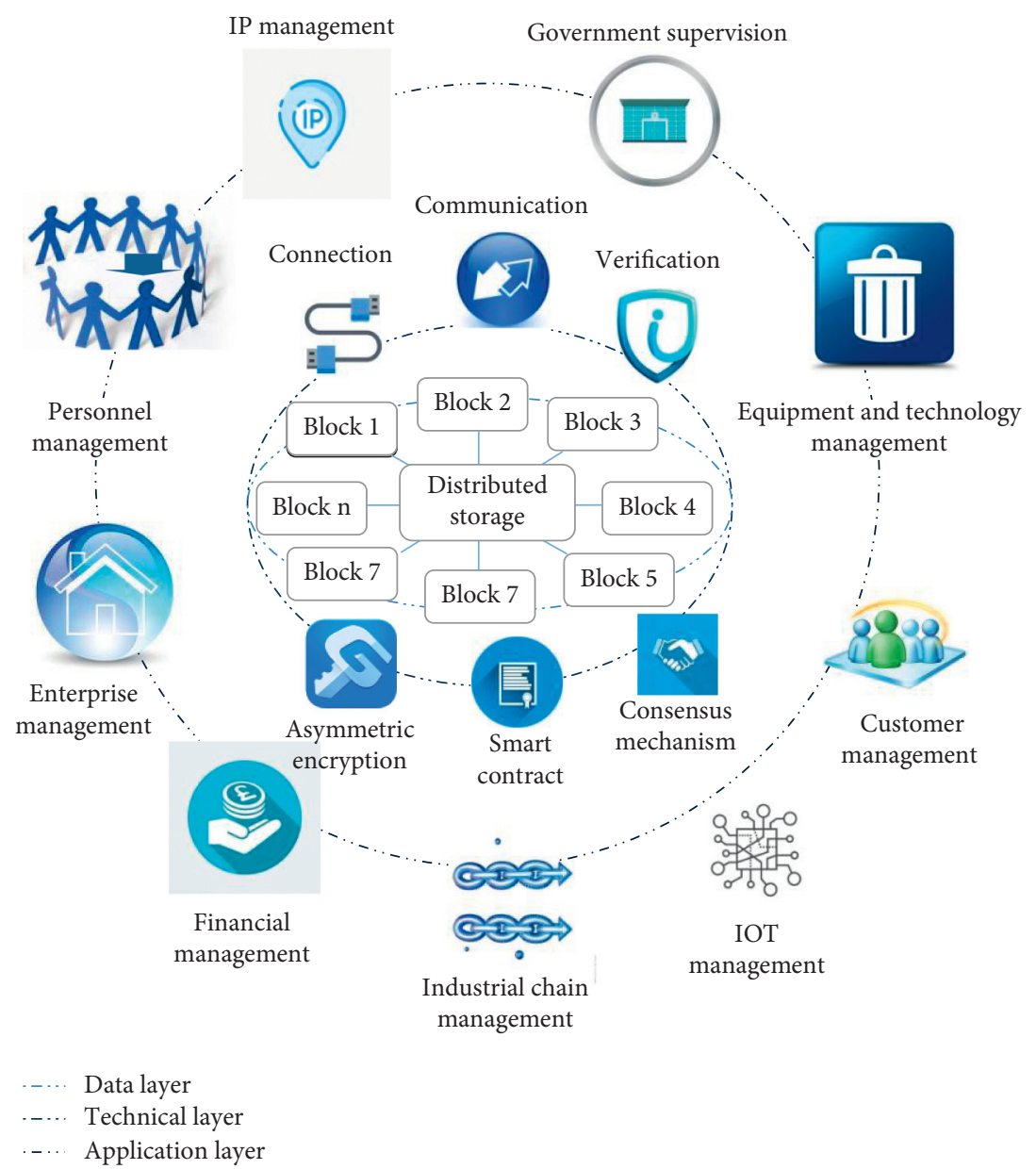

Figure 5: Programmable management system of Cultural and Creative Industry Park based on Blockchain 3.0.
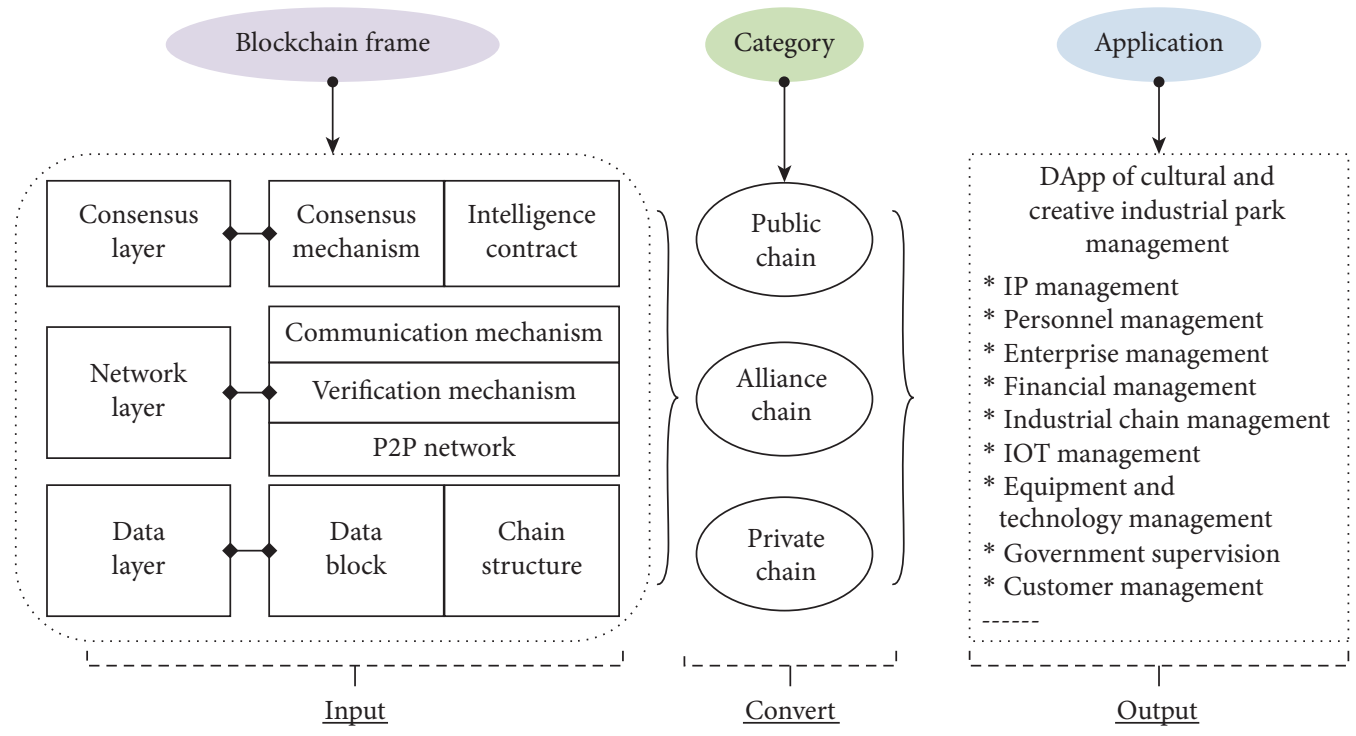

FiguRE 6: Architecture, category, and application scenario of blockchain in the management of Cultural and Creative Industrial Park.

shown in Figure 7. For example, we optimize the distribution mode of digital rights transaction income, user payment mechanism [10], reduce cross-regional infringement [11], balance the interests between copyright owners and the public, between platform intermediaries and copyright owners, and between the public and platform intermediaries 


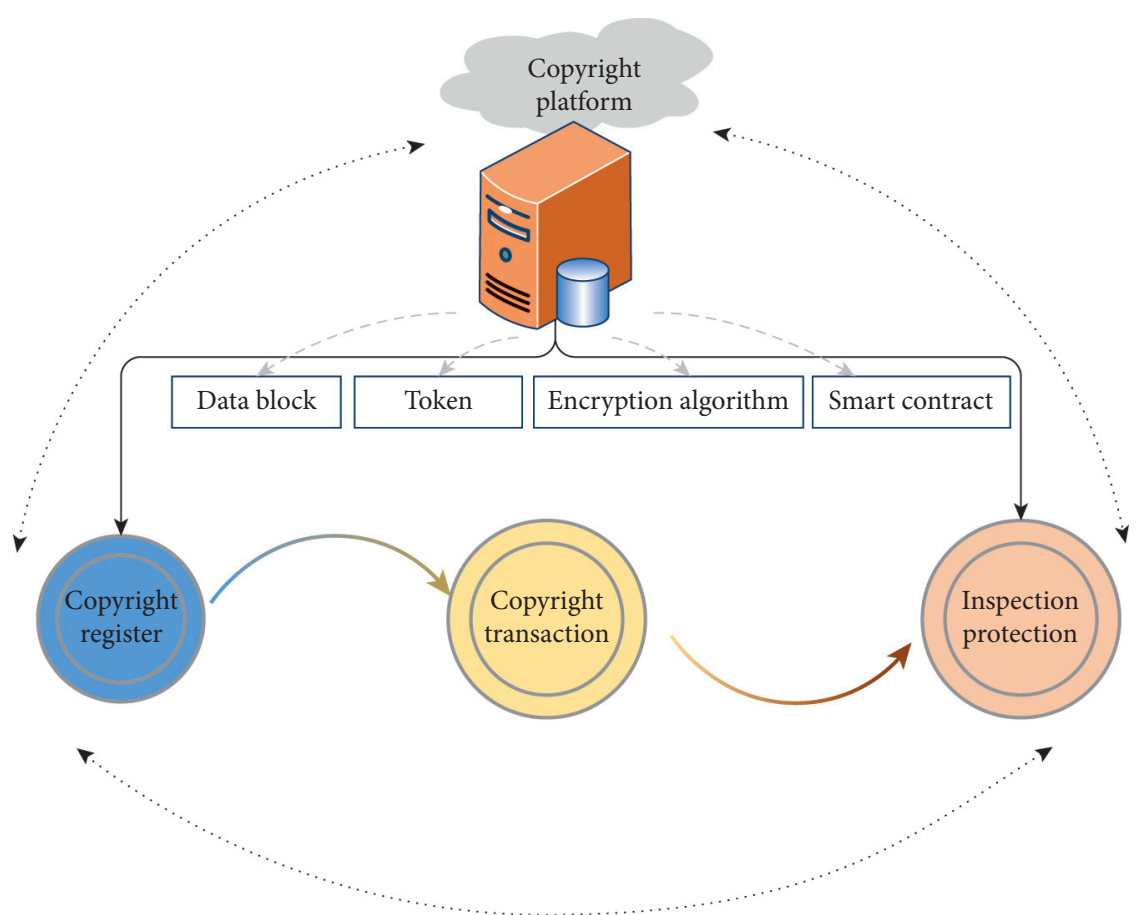

FIGURE 7: Operation mechanism and content of IP copyright management module.

[12], and automatically allocate license fees to platform intermediaries and copyright owners. At present, the more successful cases of using blockchain for intellectual property management include Annie shares, Ascribe [13], Edition Family [14], Minelabs [15], and China Copyright Protection Center.

4.2.2. Personnel Management Module. The traditional personnel file management is faced with the disadvantages of low efficiency of personnel information updating, insufficient utilization of human resources in the park, and high risk of personnel information leakage. Establishing a personnel information system in the park can record the personnel information of each enterprise and form a personnel information blockchain in the park, realize the realtime synchronous update of personnel information data [16], ensure the credibility of personnel information, protect the confidentiality of data, and improve the efficiency of human resources.

4.2.3. Enterprise/Institution Management Module. First of all, blockchain plays an important role in enterprise credit governance, which can promote transaction subjects to participate in credit governance activities [17]. Based on distributed data storage, point-to-point transmission, and other computer technologies, different nodes and platforms can share data in the system. At the same time, it can also use hash function and RSA asymmetric encryption digital signature and other technologies generate a public key and special key to protect the privacy of data information [18]. Secondly, blockchain can also participate in the life cycle management of enterprises/institutions. Establishing alliance chains at provincial and municipal levels can record the registration, change, and other information of market members, synchronize to the blockchain information network, and support business activities in the life cycle of market subject registration, major information change, major event publicity, and delisting [19]. Third, blockchain can also innovate enterprise performance management. Blockchain can solve the problems of authenticity, openness, and security in enterprise performance data management. According to the social consensus mechanism of the blockchain, the project information and data recorded on the chain will be transferred in turn to all nodes of the chain. Any change of information between nodes will cause information conflict between nodes. If you want to modify the data, you must modify more than $51 \%$ of the nodes on the blockchain at the same time to succeed [20].

4.2.4. Financial Management Module. In Ethereum, the deployment and transfer of smart contracts need to pay digital currency. Asymmetric encryption and distributed storage of blockchain technology can ensure the security of equity delivery of digital assets. With authorization, financial institutions have a clear understanding of the current accounts and historical credit records of enterprises, which fundamentally solves the biggest problem that SMEs are difficult to obtain credit loans [21]. The "blockchain + supply chain" financial service platform can also provide financing 
services for small and microenterprises in Cultural and Creative Industry Park and solve their financing difficulties [22].

4.2.5. Industrial Chain Management Module. The tamperproof property of the blockchain provides an effective solution for the anti-counterfeiting and traceability of goods [23], thus improving the trust mechanism among enterprises in the supply chain and realizing the automatic management of the supply chain transaction system [24].

4.2.6. IOT Management Module. The Internet of things (IOT) is a kind of network that connects any item with the Internet according to the agreed protocol through radio frequency identification, infrared sensors, global positioning system, laser scanner, and other information sensing devices to exchange and communicate information, so as to realize the intelligent identification, positioning, tracking, monitoring, and management of items [25]. The "blockchain + IOT" in the Cultural and Creative Industry Park can solve the pain points such as the leakage of personal privacy and the lack of trust of operators in the IOT. The organic combination of the two can make people, machines, and everything fully interconnected, and the deep integration of information technology, human, and industrial technology, so as to build a comprehensive and reliable digital industrial Internet.

4.2.7. Customer Management Module. In terms of customer management activities, the distributed data recording and sharing function of the blockchain is used to store the consumption information of customers in the park, the convenience of DAPP is used to collect customers' opinions, and the evaluation information of customers on the overall facilities and artistic atmosphere of the park in the "Art + Tourism" website is used. The art institutions in the park can more scientifically analyze consumers' behaviors, attitudes, and suggestions so as to do a better job in customer management activities.

4.2.8. Equipment and Technology Management Platform. As the technical support of the programmable management system of the Cultural and Creative Industry Park, the technical maintenance department of the blockchain is an important link to ensure the normal operation of the whole management system. Therefore, there must be professional departments and technical teams to maintain and update the cloud server, virtual host, storage service, network service, operation, and maintenance service management system related to the operation of the blockchain. At the same time, the encryption technology and smart contract of blockchain are facing the risk of being attacked by hackers. Therefore, the maintenance of blockchain network security is also an important functional module and link.

4.2.9. Government Department Supervision Module. As one of the nodes of the blockchain, the government can share the data and information of the development of the park, supervise the data of the park, evaluate the development of the park, and supervise and manage the park according to the development plan of the park.

4.3. Mechanism of Blockchain 3.0 Technology Embedded in Management Innovation of Cultural and Creative Industrial Park. Mechanism refers to the structure, function, and interrelationship of the organism. The connotation of sociology can be expressed as "the specific operation mode of coordinating the relationship between different parts in order to play a better role under the premise of facing up to the existence of each part of things". There are three mechanisms for the existence and sustainable development of any system: incentive mechanism, renewal mechanism, and supervision mechanism [26]. As a system, the programmable management system of Cultural and Creative Industrial Park has no exception.

4.3.1. Incentive Mechanism. The incentive mechanism of programmable management of Cultural and Creative Industrial Park includes internal and external dynamic mechanisms. In terms of internal dynamic mechanism, the internal demand of Cultural and Creative Industrial Park Management for the upgrading of efficient industrial chain and industrial value chain, as well as the strategic alliance formed by the intermediary organization structure of enterprises/institutions, finance, government regulatory departments, and blockchain technology departments, its power and direction goal is to continuously improve the collaborative innovation ability and obtain the competitive advantage of the alliance.

In terms of external dynamic mechanism, first of all, blockchain technology has promoted the innovation of management means in some related industries and encouraged Cultural and Creative Industrial Park to change management means; secondly, in response to the call of national planning and development, the development scope and strength of "blockchain + substantial economy" are expanded. In the white paper on the development of China's blockchain industry in 2018, MIIT proposed that blockchain is expected to promote technological, organizational, and efficiency changes in China's economic system and make important contributions to the construction of a modern economic system [8]. In January 2019, general secretary $\mathrm{Xi}$ Jinping stressed that "we must promote the deep integration of blockchains and real economies, use blockchain technology to promote greater interconnection among the city, 
and further open up the innovation chain, application chain, and value chain".

4.3.2. Update Mechanism. The operation of any system needs to be continuously developed through the updating of elements, and the dynamic organization of the management system of the programmable Cultural and Creative Industry Park also meets this requirement. The system operation of the Cultural and Creative Industry Park involves many factors, but the five factors that play a major role in the system operation are consensus mechanism, communication mechanism, confidentiality mechanism, decisionmaking mechanism, and evaluation mechanism.

The consensus mechanism is the basis of value exchange activities among node enterprises in Cultural and Creative Industry Park, which involves enterprise credit, contract formulation, and implementation. The traditional consensus mechanism is based on offline contracts and credit verification by third-party organizations, but there are some problems, such as low efficiency and complex costs. Blockchain technology provides distributed data storage, digital encryption technology, intelligent contract, script code, and other means, which makes the nodes of blockchain reach a consensus and mutual dependence, forming a credible cooperation environment. At the same time, smart contracts, electronic signatures, and other technologies can help to complete the contract verification and performance and realize an efficient and secure online consensus working mechanism. At present, consensus mechanisms for blockchain creation mainly include PoW, PoS, Dpos, and distributed consistency algorithm.

The communication mechanism is a way for enterprises/ institutions in the Cultural and Creative Industry Park to carry out information exchange. The information-sharing convenience brought by the distributed storage of the blockchain and the information security guarantee brought by digital encryption enable the information communication and exchange between and within the Cultural and Creative Industry Park to realize the P2P (peer-to-peer) communication mode. The relevant information of enterprises can be directly obtained from the blockchain, and there is no need to repeatedly query and confirm with relevant institutions, which is of great value and significance for efficient information dissemination and exchange.

The traditional information security work is in the charge of the people-centered organization department, which has objective risk. There are three types of blockchain, namely public chain, alliance chain, and private chain, which can provide data security support from different areas. Asymmetric encryption technology, hash function, and digital signature can support limited access rights, control the access rights of some stored data between limited nodes, and achieve decentralized, safe, and efficient security work.

In addition, blockchain has also changed the subjective errors such as perceptual errors and data fraud hidden in the traditional people-centered decision-making mechanism and evaluation mechanism in the Cultural and Creative Industry Park. The storage of distributed data greatly improves the authenticity and nontamperability of data, making the decision-making in the Cultural and Creative Industry Park more scientific and objective and the evaluation more authentic.

4.3.3. Supervision Mechanism. The supervision department in the operation of the management system of Cultural and Creative Industrial Park is essential, whether it is the internal supervision organization of the enterprise or the external supervision organization of the government or the social supervision organization. The internal decision-making mechanism refers to the supervision and governance mechanism for the internal development of enterprises or parks to monitor and manage the personnel, financial data, revenue, and expenditure data, while the external supervision mechanism refers to the mechanism for the government and social organizations to evaluate and supervise the development data of Cultural and Creative Industrial Park. The distributed data storage of blockchain provides convenient, reliable, and tamperable basic data for supervision information, which can change the inefficiency and information asymmetry of traditional supervision mechanisms.

\section{Conclusion}

(1) The "decentralization" concept of blockchain can provide guidance value for the management concept innovation of Cultural and Creative Industry Park, and the embedding of technologies such as smart contract, distributed ledger, and digital currency can promote the construction of "programmable Cultural and Creative Industry Park management system."

(2) The Cultural and Creative Industry Park introduces Blockchain 3.0 technology to carry out management innovation along the path of structure, function, and application. The architecture of the consensus layer, network layer, and data layer of the blockchain is not only the hierarchical structure of the blockchain of the park but also provides a support platform for the management informatization of the park. The functional system construction of public chain, alliance chain, and private chain provides support conditions for the lean management of the park. IP copyright management, enterprise/institution management, industrial chain management, government supervision management, and other activities provide clear application scenarios and management innovation direction for blockchain being applied in the park.

(3) The blockchain in Cultural and Creative Industry Park constructs the system architecture through consensus layer, network layer, and data layer. The consensus layer of the blockchain in the park enables the main bodies of the park to establish a consensus on the operation of the park through joint efforts, and the management and technical means such as "consensus mechanism" and "intelligent contract" 
are used to guarantee the management activities. The network layer constitutes the basic carrier of the blockchain of the park and becomes the technical means to realize the management activities of the park. The role of the data layer is to provide data basis for the realization of the digital sharing economy in the park by establishing decentralized cloud storage.

(4) Different levels of blockchain in Cultural and Creative Industry Park can promote different levels of management innovation. The public chain can solve the problem of information asymmetry in the park from the strategic level, cultivate an efficient selforganization management system, and promote the integration and upgrading of the industrial value chain in the park. Alliance chain can provide a mature and reliable data sharing system for organization operation, eliminate the credit barriers between enterprise nodes, and build an efficient value exchange system and evaluation system. Private chain mainly provides data sharing, credit guarantee mechanism, and technical services for enterprises and teams at the microlevel.

(5) Cultural and Creative Industry Park can implement management innovation through blockchain construction and its combination with the park management system. The blockchain of the park is constructed and operated based on consensus mechanism, intelligent contract mechanism, connection mechanism, communication mechanism, verification mechanism, and other mechanisms. Through the mutual embedding and collaboration between the blockchain information platform and the park management system, it supports the park to implement management innovation.

\section{Data Availability}

The data used to support the findings of this study are available from the corresponding author upon request.

\section{Conflicts of Interest}

The authors declare that they have no conflicts of interest regarding the publication of this paper.

\section{Acknowledgments}

The authors acknowledge with gratitude the Initial Scientific Research Fund of Hubei University of Technology for Doctors (no. BSQD20200070) and Project of Wuhan Federation of Social Sciences (WHSKL2021140). This study would not have been possible without their financial support.

\section{References}

[1] M. Swann, Blockchain: Blueprint for a New Economy New Economic, pp. 13-26, O’Reilly Media, Inc., Newton, MA, USA, 2016.
[2] M. Sharples and J. Domingue, "The blockchain and kudos: a distributed system for educational record, reputation and reward, adaptive and adaptable learning," in Proceedings Of The European Conference on Technology Enhanced Learning, pp. 490-496, Leeds, UK, September 2016.

[3] K. Christidis and M. Devetsikiotis, "Blockchains and smart contracts for the internet of things," IEEE Access, vol. 4, pp. 2292-2303, 2016.

[4] S. A. Renu and B. G. Banik, "Implementation of a secure ridesharing DApp using smart contracts on Ethereum blockchain," International Journal of Safety and Security Engineering, vol. 11, no. 2, pp. 167-173, 2021.

[5] J. Q. Zhang and R. H. Luo, "Application of blockchain in artist mutual trust," Market Weekly: Theoretical Research, vol. 1, pp. 112-114, 2020.

[6] F. Yu, C. Li, and J. Chen, "Reconstruction of ceramic art design copyright trading platform based on blockchain technology," Journal of Ceramics, vol. 41, no. 3, pp. 436-441, 2020.

[7] J. Wang, "Application and research of blockchain technology in the field of art authentication and traceability," Computer Products and Circulation, vol. 1, pp. 283-286, 2020.

[8] Information Center of Ministry of Industry and Information Technology, "White Paper on China's Blockchain Industry Development in 2018," EB, pp. 1-13, 2018.

[9] H. L. Wei, Research on the Evolution Path of Art Industry Value Chain from the Perspective of Cluster, pp. 123-125, Wuhan University of technology, Wuhan, China, 2020.

[10] M. Holland, C. Nigischer, and J. Stjepandic, "Copyright protection in additive manufacturing with blockchain approach," Transdisciplinary Engineering: A Paradigm Shift, vol. 5, pp. 914-921, 2017.

[11] Z. F. Y. Yu, "Research on intellectual property protection model based on blockchain technology," Network Mobile Office and Home Office, vol. 7, pp. 32-36, 2020.

[12] L. N. Li and Y. M. Li, "Opportunities, challenges and development path of digital copyright protection under blockchain technology," Research on the Rule of Law, vol. 4, pp. 127-135, 2020.

[13] Q. X. Meng and Y. J. Wu, "The way of technology in network copyright trading from blockchain's perspective," Publishing Journal, vol. 25, no. 6, pp. 25-31, 2017.

[14] J. J. Tang, "Application prospect of blockchain technology in publishing industry," China Editor, vol. 7, pp. 42-45, 2020.

[15] J. Sun, "The current situation of digital infringement and copyright protection of Sci-tech Journals: a preliminary study on the feasibility of blockchain technology," Research on Chinese Sci-Tech Journals, vol. 10, pp. 1000-10005, 2018.

[16] Q. Z. Li and L. Han, "Preliminary study on the application of 'blockchain+personnel archives' management," Academic Forum, vol. 7, pp. 73-76, 2020.

[17] B. Lainjo, "Network security and its implications on program management," International Journal of Safety and Security Engineering, vol. 10, no. 6, pp. 739-746, 2020.

[18] A. Anjum, M. Sporny, and A. Sill, "Blockchain standards for compliance and trust," IEEE Cloud Computing, vol. 4, no. 4, pp. 84-90, 2017.

[19] B. Jæger, T. Bach, and S. A. Pedersen, "A blockchain application supporting the manufacturing value chain," in Proceedings of the IFIP International Conference on Advances in Production Management Systems, pp. 466-473, Austin, TX, USA, September 2019.

[20] M. Iansiti and K. R. Lakhani, "The truth about blockchain," Harvard Business Review, vol. 1, pp. 118-127, 2017. 
[21] D. Yermack, "Corporate governance and blockchains," Review of Finance, vol. 21, no. 1, pp. 7-31, 2017.

[22] P. Treleaven, R. Gendal Brown, and D. Yang, "Blockchain technology in finance," Computer, vol. 50, no. 9, pp. 14-17, 2017.

[23] K. Korpela, J. Hallikas, and T. Dahlberg, "Digital supply chain transformation toward blockchain integration," in Proceedings of the 50th Hawaii International Conference on System Sciences, pp. 4182-4191, Hilton Waikoloa Village, HI, USA, August 2017.

[24] D. M. Lambert and M. G. Enz, "Issues in supply chain management: progress and potential," Industrial Marketing Management, vol. 62, pp. 1-16, 2017.

[25] A. Ouaddah, A. A. Ouahman, and A. A. Ouahman, "Towards a novel privacy-preserving access control model based on blockchain technology in IoT," Advances in Intelligent Systems and Computing, vol. 520, pp. 523-533, 2017.

[26] J. L. Zhu and Y. F. Peng, "The research on organization mode and operation mechanism of innovation network in cooperation of industry university and research institute," Soft Science, vol. 17, no. 4, pp. 49-52, 2003. 